\title{
APPLICATION OF A PHYSIOTHERAPEUTIC PROGRAM IN CHILDREN WITH PNEUMONIA
}

\author{
Nezabravka Gencheva ${ }^{1}$, Ani Malinova ${ }^{2}$, Rositsa Mitrova ${ }^{2}$ \\ National Sports Academy "Vassil Levski" ${ }^{1}$ \\ University Hospital "Lozenetz" 2
}

\begin{abstract}
Introduction
Pneumonia is a pulmonary system disease with an unusually great number of various etiologic agents. Regardless of continuous advances in medicine, pneumonia continues to be a serious challenge to diagnose and to treat, even if it is identified in time and treatment is undertaken in due course.
\end{abstract}

The peculiarities of the infant constitution in the different stages of the early age provoke various preconditions for an explicitly defined specific character of the disease course. (Bobev, Ganev, 2000). Vastly increased share of viral and virus-bacterial pneumonia complicates the process of disease course per se, as well as the pneumonia medication in the children-aged group (Minchev, 1999). Pneumonia is still a serious illness among the children and the grow-ups even today and continues to be a challenge and great responsibility for all involved in the curing process; in this respect, it is of great obligation for the physiotherapists as well. Morrison, Agnew (2011) share that even after the inflammation process fades away recuperation of the child body functions takes a long time and is accompanied by a reduced effectivity of the respiratory system, obstruction, etc.

Chest physiotherapy is an important part of the treatment of most respiratory diseases (Balachandran et al, 2005) and is commonly used in children with chronic respiratory disease. According to Morrison, Agnew (2011) physiotherapy can be classified as conventional, modern and instrumental techniques. The aim of Chest Physiotherapy is to facilitate mucociliary clearance (Main 2009). The use of Physiotherapy (PT) in pediatric pneumonia helps to eliminate the inflammatory exudates and tracheobronchial secretions, eliminate airway obstruction, reduce their resistance, improve gas exchange, and normalize breathing (Chaves, 2013). The information in literature sources regarding the physiotherapy application to children with pneumonia is rather contradictory as for the type of the pneumonia, the duration of the physiotherapeutic treatment, the selection of physiotherapeutic techniques, as well as with respect to statistical research data, etc. Moreover, there is no persuasive evidence that may support or refute the application of physiotherapy to children with pneumonia. Each illness decreases motor activity and disadvantageously influences on the growing organism (mainly on the cardiovascular system and respiratory system), averts activation of sanogenesis mechanisms (Hrushchev, Simeonova, 2006). It is necessary to pay attention also to the stimuli needed for the general psycho and physiological development of the child; its progress may be retarded due to the affection process.

The aim of the study is to monitor the effect of PT in combination with medication therapy in children with pneumonia

Methodology of the research: A Physiotherapy Program was applied to 7 children of average age of 8,4 years old, diagnosed as suffering from viral pneumonia that was radiographically proven immediately after their entrance in the Lozenetz University Hospital, and prescribed instruction for 3-4-day hospitalization and respective medical treatment. We compared the results got in this group with the data from a control group of 6 children of average age 7.5 years' old who were under medication treatment at home. History of the presenting illness, like cough, fever, fast/difficulty in breathing, chest pain, and inability to feed were documented.

\section{Research Methods:}

After being hospitalized and after the relevant clinic checkups and diagnosing, at the beginning of the medical treatment course and at the end of it the children in both groups - the experimental and the control - were thoroughly examined by using the following tests: Physical inspection of the breath frequency, where as a measure unit was used the number of motion of the thoracic cavity (cavum thoracis) per minute at the beginning and the end of the therapy course; Spirometry necessary to test 
lung functionality, specifically the volume and the flow of air that can be inhaled and exhale; thus we defined the Forced vital capacity (FVC) and forced expiratory volume per one second (Forced expiratory volume during the first second (FEV1)); Respiratory rate in centimeters, in state of maximum inhalation; Measuring and evaluation of hemodynamic indicators such as pulse frequency and arterial blood pressure; Oxygen blood saturation (O sat) of the patients was measured using pulse oximeter with appropriately sized pediatric probe. Hypoxemia was defined as O sat $<90 \%$; Computer mathematic and statistic processing of the final test data with the help of standard processing programs such as SPSS12.0. and Microsoft Excel, on PC.

\section{Physiotherapy Methodology}

The final kinesitherapeutic goal is to recover the respiratory functionality and recreation of children's vitality. Having in mind all peculiarities of child's breathing physiology, we worked out a physiotherapy programme (PTP) especially for the group of children with pneumonia in clinic conditions; there we included the experimental group (EG). The children from the control group (KG) did not conduct physiotherapy because after assigned parents' consent, they were discharged from the hospital for home treatment and came back to the clinic for control checkups just in the end of the medical therapy. The PT Program includes inhalation treatment, Huff Cough Technique, drainage massage, various games, imitation exercises and static or dynamic breathing exercises using positions on Physio Roll. After the inhalation treatment PT Program continued with Huff Cough Technique: this is a technique helping the mucus (muscles secretion) to move out from the lungs. It may be individually exercised by the patient. This technique must be repeated two or more times and followed by a strong cough to clear the mucus from the larger airways. The whole cycle is repeating up to four or five Huff coughs. We decided to employ exercises with Physio Roll, because it has the form of a peanut; this shape allows the child to hold different positions and gives chance the lung to be drained. Moreover, the exercises with such a ball represent a holistic motive experience and help to build up a good body position, coordination, balance and muscle strength. The children explore their environment while moving around in the space (Ceron, 2003). By the usage of the low frequency fluctuations, passively got by the patients while performing the ball exercises, they get their spastic muscles on the back and the cervix relaxed. Jumping up and down on the ball with a clear-cut tempo helps them to improve their sense of rhythm. Sitting on the ball is a dynamic action and provokes the young body to keep a correct and proper pose for a long time (Gencheva, Zaharieva, 2014). The exercises with Physio Roll are more easily accepted by the little patients and they are more willing to practice them. These exercises create positive emotions in them - in most cases they are perceived and played as games and imitation exercises; and so, without any doubt, they give a chance the child to improve his/her activity while carrying out different and various dynamic and respiratory exercises in a set (Gencheva, 2003). Massage was also conducted using the Physio Roll before to start performing the whole gymnastic complex. We situated the children in a suitable body position with respect to the affected lung segment and so provided the needed declination of the segmented draining bronchi to the joints, the roots of the bronchial tree. Draining was facilitated by cough and diaphragm breathing in a draining position. We applied also vibration techniques and patting the thorax in the respective affected segment. The vibrations and the pats we carried out during the expiation phase. Physiotherapeutic procedures were carried out simultaneously in combination with medicated treatment: antipyretics, anti-coughing medicines, vitamins, one or two antibiotics.

\section{Results and discussion}

In Table 3 and Table 4 we present the results from the spirometry, breathing frequency and chest inhalation measurements (CHIM) at the beginning and end of the treatment course respectively in the experimental and control groups. The data in the beginning of the treatment, obtained prior to the appointment of a kinezitherapeutic treatment point out the fact that all children have had decreased FVC and more distinctly a decrease in the forced expiratory volume in one second (FEV1). The FEV1/ FVC ratio (Tiffeneau Index) manifests a presence of a sort of obstructive pulmonary insufficiency $(72,14 \%$ in EG and $73 \%$ in $\mathrm{KG})$. 
Table 3 Changes in respiratory parameters in EG children with pneumonia at the beginning and end of treatment in EG

\begin{tabular}{|c|c|c|c|c|c|c|c|}
\hline \multirow{2}{*}{$\begin{array}{c}\text { EG } \\
\text { Parameters }\end{array}$} & \multicolumn{2}{|c|}{ Beginning of treatment } & \multicolumn{2}{|c|}{ End of treatment } & \multirow{2}{*}{ d } & \multirow{2}{*}{$\mathbf{t}_{\text {emp }}$} & \multirow{2}{*}{$\mathbf{P} \%$} \\
\hline & $\bar{X}_{1}$ & $\mathbf{S}$ & $\bar{X}_{2}$ & $\mathbf{S}$ & & & \\
\hline FVC & 1978,57 & 208,35 & 2175,57 & 183,52 & $-197,00$ & $-4,379$ & $99,5 \%$ \\
\hline FEV1 & 1422,71 & 118,43 & 1682,43 & 170,85 & $-259,71$ & $-7,419$ & $99,0 \%$ \\
\hline FEV1/ VC & 72,14 & 4,85 & 77,29 & 4,39 & $-5,14$ & $-4,076$ & $99,3 \%$ \\
\hline Ross. Rate & 23,86 & 3,81 & 19,57 & 2,15 & 4,29 & 6,301 & $99,9 \%$ \\
\hline CHIM & 71,28 & 2,81 & 72,57 & 2,57 & $-1,29$ & $-6,971$ & $99,9 \%$ \\
\hline
\end{tabular}

Table 4 Changes in respiratory parameters in EG children with pneumonia at the beginning and end of treatment in KG

\begin{tabular}{|c|c|c|c|c|c|c|c|}
\hline \multirow{2}{*}{$\begin{array}{c}\text { KG } \\
\text { Parameters }\end{array}$} & \multicolumn{2}{|c|}{ Beginning of treatment } & \multicolumn{2}{|c|}{ End of treatment } & \multirow{2}{*}{ d } & \multirow{2}{*}{$t_{\text {emp }}$} & \multirow{2}{*}{$\mathbf{P} \%$} \\
\hline & $\bar{X}_{\mathbf{1}}$ & $\mathbf{S}$ & $\bar{X}_{2}$ & $\mathbf{S}$ & & & \\
\hline FVC & 1921,83 & 224,97 & 2059,50 & 201,49 & $-137,67$ & $-4,454$ & $99,3 \%$ \\
\hline FEV1 & 1391,67 & 72,46 & 1524,8333 & 109,43 & $-133,17$ & $-4,956$ & $99,6 \%$ \\
\hline FEV1/ VC & 73,00 & 5,80 & 73,83 & 4,26 &,- 83333 &,- 412 & $30 \%$ \\
\hline Ross. Rate & 23,83 & 3,92 & 21,50 & 1,87 & 2,33 & 2,445 & $94,2 \%$ \\
\hline CHIM & 70,83 & 1,84 & 71,50 & 2,16 & $-0,67$ &,- 649 & $44,8 \%$ \\
\hline
\end{tabular}

At the beginning of the research work it may be seen that the respiratory frequency in EG and KG is above the values registered for the respected age group (23,86 acts/min and 23,83 acts/min) Due to the medical therapy and the applied kinesitherapeutic Program FVC and FEV1 increase and in the end of treatment are more close to the standard Statistically significant differences were observed between initial and fi-

nal values of all tested breathing parameters in the (CHIM) $(\mathbf{P}=\mathbf{4 4 , 8 \%})$.

experimental group $(\mathrm{P}>99 \%)$. Statistically insignificant differences between initial and final values Table 5 and Table 6 present the comparison befor PT group were found only for FVC and FEV1. tween the results of spirometry, respiratory rate, Statistically insignificant differences between initial and chest inhalation measurements between EG and final values for KG were found for Respiratory and KG, respectively, at the beginning and end of rate $(\mathbf{9 4 , 2 \% )}$ and Chest inhalation measurements the treatment course.

Table 5 Comparison between the results of spirometry, respiratory rate, and chest inhalation measurements between EG and KG, respectively, at the beginning of treatment

\begin{tabular}{|c|c|c|c|c|c|c|c|}
\hline \multirow[b]{2}{*}{ Parameters } & \multicolumn{2}{|c|}{$\begin{array}{c}\text { EG } \\
n=7\end{array}$} & \multicolumn{2}{|c|}{$\begin{array}{l}\mathrm{KG} \\
\mathbf{n}=\mathbf{6}\end{array}$} & \multirow{2}{*}{ d } & \multirow{2}{*}{$t_{\text {emp }}$} & \multirow{2}{*}{ P\% } \\
\hline & $\bar{X}_{\mathbf{1}}$ & S & $\bar{X}_{\mathbf{2}}$ & $\mathbf{S}$ & & & \\
\hline FVC & 1978,57 & 208,35 & 1921,83 & 224,97 & $-56,74$ &,- 472 & $53 \%$ \\
\hline FEV1 & 1422,71 & 118,43 & 1391,67 & 72,46 & $-31,04$ &,- 557 & $44 \%$ \\
\hline FEV1/ VC & 72,14 & 4,85 & 73,00 & 5,80 &, 86 & ,291 & $22 \%$ \\
\hline RES Rate & 23,86 & 3,81 & 23,83 & 3,920 &,- 03 &,- 011 & $01 \%$ \\
\hline CHIM & 71,28 & 2,81 & 70,83 & 1,84 &,- 45 &,- 336 & $26 \%$ \\
\hline
\end{tabular}


Table 6 Comparison between the results of spirometry, respiratory rate, and chest inhalation measurements between EG and KG, respectively, at the end of treatment

\begin{tabular}{|c|l|l|l|l|l|l|l|}
\hline \multirow{2}{*}{ Parameters } & \multicolumn{2}{|c|}{$\begin{array}{c}\text { EG } \\
\text { n=7 }\end{array}$} & \multicolumn{2}{c|}{$\begin{array}{c}\text { KG } \\
\text { n=6 }\end{array}$} & \multirow{2}{*}{ d } & \multirow{2}{*}{$\mathbf{t}_{\text {emp }}$} & \multirow{2}{*}{ P\% } \\
\cline { 2 - 7 } & $\bar{X}_{\mathbf{1}}$ & $\mathbf{S}$ & $\bar{X}_{\mathbf{2}}$ & $\mathbf{S}$ & & & \\
\hline FVC & 2175,57 & 183,52 & 2059,50 & 201,49 & $-116,07$ & $-1,087$ & $70 \%$ \\
\hline FEV1 & 1682,43 & 170,85 & 1524,83 & 109,43 & $-157,60$ & $-1,938$ & $93 \%$ \\
\hline FEV1/ VC & 77,29 & 4,39 & 73,8333 & 4,262 & $-3,45$ & $-1,433$ & $82 \%$ \\
\hline RES Rate & 19,57 & 2,15 & 21,50 & 1,87 & 1,93 & 1,710 & $89 \%$ \\
\hline CHIM & 72,57 & 2,5 & 71,50 & 1,87 & $-1,071$ & $-1,044$ & $56 \%$ \\
\hline
\end{tabular}

In the beginning, there is not date differences in spi- to the experimental group in the end of the study, rometry, respiratory rate, and chest inhalation measurements between EG and KG. But in the end of treatment there is a strong tendency for better FEV1 values in the experimental group vs. control which is result of the medical therapy and the applied kinesitherapy program with fit-ball, although the difference is statistically insignificant $(\mathrm{P}=93 \%)$. To reach a complete normalization of the Tiffeneau index levels and to achieve the foreseen values of FVC and FEV1 we recommended a set of respiratory exercises for the spirometry proceeding; these exercises are practiced in home environment. In the control group, without physiotherapy, spirometry values were lower.

Although at the time of discharging from the hospital the average values are in the norms of the upper borderline limits for the respective age standard because of the slow diminishing disease process, the difference in respiratory rate between our patients from the experimental and control groups is statistically unreliable. In the control group, we have registered higher respiratory frequency compared as well as insignificant differences compared to the first measurement. This is a manifestation that the respiratory techniques do have their positive impact on the reduction of the respiratory frequency and on deepening the breathing itself, as well. The results thorax measuring in maximum inspiration, demonstrate forced respiratory muscle system at the end of the treatment course in the PT group. The distance is almost one centimeter and this is an excellent result for a short-term treatment. $(\mathrm{P}=$ $\mathbf{9 9 , 9 \% ) . ~ S u c h ~ a n ~ i m p r o v e m e n t ~ i s ~ n o t ~ r e g i s t e r e d ~ i n ~}$ the control group

( $\mathrm{P}=94,2 \%)$ because specialized exercises for strengthening the respiratory muscle system are not included in the set.

In the beginning of the treatment course the children either from the control or from the experimental group manifests tachycardia (tabl.7-8). A serious reason for this may be the sub febrile temperature of some of the children.

Table 7 Changes in pulse rate, arterial blood pressure and oxygen saturation in children at the beginning and end of the therapeutic course in EG

\begin{tabular}{|c|c|c|c|c|c|c|c|}
\hline \multirow{2}{*}{$\begin{array}{c}\text { EG } \\
\text { Parameters }\end{array}$} & \multicolumn{2}{|c|}{ Beginning of treatment } & \multicolumn{2}{|c|}{ End of treatment } & \multirow{2}{*}{ d } & \multirow{2}{*}{$\mathbf{t}_{\text {emp }}$} & \multirow{2}{*}{$\mathbf{P} \%$} \\
\hline & $\bar{X}_{1}$ & $\mathbf{S}$ & $\bar{X}_{2}$ & $\mathbf{S}$ & & & \\
\hline PP & 100,29 & 9,10521 & 85,86 & 6,47 & 14,43 & 7,220 & $99,9 \%$ \\
\hline RR sis & 105,71 & 9,76 & 107,14 & 11,50 & $-1,43$ &,- 679 & $47,8 \%$ \\
\hline RR dias & 61,43 & 4,76 & 66,43 & 5,56 & $-5,00$ & $-3,240$ & $98,2 \%$ \\
\hline Or sat $\%$ & 89,29 & 1,60 & 94,86 & 1,46 & $-5,67$ & $-2,456$ & $99.9 \%$ \\
\hline
\end{tabular}


Table 8 Changes in pulse rate, arterial blood pressure and oxygen saturation in children at the beginning and end of the therapeutic course in KG

\begin{tabular}{|c|c|c|c|c|c|c|c|}
\hline \multirow{2}{*}{ KG } & \multicolumn{2}{|c|}{ Beginning of treatment } & \multicolumn{2}{|c|}{ End of treatment } & \multirow{2}{*}{$\mathbf{d}$} & \multirow{2}{*}{$\mathbf{t}_{\text {emp }}$} & \multirow{2}{*}{$\mathbf{P \%}$} \\
\cline { 2 - 5 } Parameters & $\bar{X}_{\mathbf{1}}$ & $\mathbf{S}$ & $\bar{X}_{\mathbf{2}}$ & $\mathbf{S}$ & & & \\
\hline PP & 99,83 & 8,84 & 91,67 & 6,77 & 8,16 & 3,024 & $97,1 \%$ \\
\hline RR sis. & 104,17 & 7,36 & 105,00 & 9,49 &,- 83 &,- 415 & $30,5 \%$ \\
\hline RR dias. & 60,83 & 5,85 & 64,17 & 4,92 & $-3,33$ & $-2,000$ & $89,8 \%$ \\
\hline Or sat\% & 92,17 & 1,47 & 93,83 & 0,98 & $-1,67$ & $-5,000$ & $99 \%$ \\
\hline
\end{tabular}

The pulse frequency normalization, with statistical children in the control group is reflected by higher reliability in $\mathrm{EG}(\mathrm{P}=99,9 \%)$ and in $\mathrm{KG}(\mathrm{P}=97,1 \%)$ values of the pulse frequency as a compensatory is due to the reduction of the body temperature and mechanism, but the differences are statistically reto the increase in the compensatory mechanisms of liable. The difference in arterial blood pressure bethe heart vascular system while the loading is grow- tween our patients from the experimental and coning up. The lack of a direct physical loading for the trol groups is statistically unreliable (Tabl. 9-10).

Table 9 Comparison of pulse rate, arterial blood pressure and oxygen saturation in children in EG and $K G$ at the beginning of therapeutic course

\begin{tabular}{|c|c|c|c|c|c|c|c|}
\hline \multirow[b]{2}{*}{ Parameters } & \multicolumn{2}{|c|}{$\begin{array}{l}\text { EG } \\
\mathrm{n}=7\end{array}$} & \multicolumn{2}{|c|}{$\begin{array}{l}\mathrm{KG} \\
\mathbf{n}=\mathbf{6}\end{array}$} & \multirow[t]{2}{*}{ d } & \multirow[t]{2}{*}{$t_{\text {emp }}$} & \multirow[t]{2}{*}{$\mathbf{P} \%$} \\
\hline & $\bar{X}_{1}$ & $\mathbf{S}$ & $\bar{X}_{2}$ & S & & & \\
\hline PP & 100,29 & 9,10521 & 99,83 & 8,84 &,- 090 &,- 452 & $7 \%$ \\
\hline RR sis. & 105,71 & 9,76 & 104,17 & 7,36 & ,757 &,- 318 & $24 \%$ \\
\hline RR dias. & 61,43 & 4,76 & 60,83 & 5,85 &,- 595 &,- 203 & $16 \%$ \\
\hline Or sat\% & 89,29 & 1,60 & 92,17 & 1,47 & 2,88 & 3,351 & $99.4 \%$ \\
\hline
\end{tabular}

Hypoxaemia (Osat $<90 \%$ ) was observed in the chil- treatment course, $\mathrm{O}$ sat at the EG was in norm. dren of the EG and they were hospitalized. The KG (O sat=94.86\%) as the growth was greater comsubjects were targeted for home treatment because pared to the control group.

the $\mathrm{O}$ sat values were about $92 \%$. At the end of the

Table 10 Comparison of pulse rate, arterial blood pressure and oxygen saturation in children in EG and KG at the end of therapeutic course

\begin{tabular}{|c|c|c|c|c|c|c|c|}
\hline \multirow[b]{2}{*}{ Test } & \multicolumn{2}{|c|}{$\begin{array}{l}\text { EG } \\
\mathbf{n}=7\end{array}$} & \multicolumn{2}{|c|}{$\begin{array}{l}\text { KG } \\
\mathrm{n}=6\end{array}$} & \multirow{2}{*}{ d } & \multirow{2}{*}{$t_{\text {emp }}$} & \multirow{2}{*}{ P\% } \\
\hline & $\bar{X}_{\mathbf{1}}$ & S & $\bar{X}_{2}$ & S & & & \\
\hline PP & 85,86 & 6,47 & 91,67 & 6,77 & 5,81 & 1,580 & $86 \%$ \\
\hline RR sis & 107,14 & 11,50 & 105,00 & 9,49 & $-2,14$ &,- 362 & $28 \%$ \\
\hline$R R$ diast & 66,43 & 5,56 & 64,17 & 4,92 & $-2,26$ &,- 770 & $55 \%$ \\
\hline $\mathrm{O}^{r}$ sat & 94,86 & 1,46 & 93,83 & 0,98 & $-1,02$ & $\mid-1,451$ & $82.5 \%$ \\
\hline
\end{tabular}




\section{Conclusion}

The applied physiotherapeutic program includes a broad spectrum of physical exercises with PhysioRoll, respiration techniques and massage for children with pneumonia in a clinic environment; such physical exercises accelerate the process of rehabilitation the correct breathing and the hemodynamic criteria such as pulse frequency and arterial blood pressure in the group of children with pneumonia. The lack of specialized respiratory rehabilitation for the respiratory diseases should not be disregarded; it may have a negative reflection both - on the recovery process as well as on the normal psycho-physical development of the children.

\section{Bibliography}

Bobev Dr, Ganev E (2000) Pediatria for students of medicine, Arso. 3 th ed.Sofia

Gencheva N., (2003) Fit-ball and Kinesithgerapy, BulIns, Sofia

Gencheva N, Zaharieva D. (2013) The Fit-ball balance training in children with bad posture, FIS Communications, book of proceedings, Nis, October, pp: 257-263

Minchev P (1999) Pneumonia in childhood -Diagnostic and Therapeutic Problems; Practical pediatria, 4 pp: 5

Hrushev S., Simeonova O (2006) Физическая культура детей с заболеваниями органов дыхания, Академия, M.

Balachandran A, Shivbalan S, Thangavelu S. (2005) Chest physiotherapy in pediatric practice. Indian Pediatrics;42, pp:559-68.

Chaves G, Fregonezi, G; AL Dias, F; Ribeiro, C; Guerra, R; Freitas, D; Parreira, V Mendonca.K (2013) Chest physiotherapy for pneumonia in children, Cochrane Database of Systematic Reviews (CDSR), 9,, available at: DOI:10.1002/14651858.CD001401.pub2 (accessed 12
August 2017)

Gajdos V, Katsahian S, Beydon N, Abadie V, de Pontual L, Larrar S, Epaud R, Chevallier B, Bailleux S, Mollet-Boudjemline A, Bouyer J, Chevret S, Labrune P. (2010) Effectiveness of chest physiotherapy in infants hospitalized with acute bronchiolitis: a multicenter, randomized, controlled trial. PLoS Med. 7(9); pp:1-12

Duke, T.; Mgone, J.; Frank, D.(2001) Hypoxaemia in children with severe pneumonia in Papua New Guinea [Oxygen Therapy in Children] The International Journal of Tuberculosis and Lung Disease, 5/ 6, 2001, pp: 511-519 accessed 16 August 2017

Main E, Prasad A, van der Schans C (2009), Conventional chest physiotherapy compared to other airway clearance techniques for cystic fibrosis. Cochrane Database of Systematic Reviews, Issue 2. available at: DOI: 10.1002/14651858.CD002011.pub2 (accessed 12 August 2017).

Michelow IC, Olsen K, Lozano J, et al. Epidemiology and clinical characteristics of community-acquired pneumonia in hospitalized children. Pediatrics. 2004;113:701707

Morrison L, Agnew J. (2011) Oscillating devices for airway clearance in people with cystic fibrosis. Cochrane Database of Systematic Reviews, Issue 1. available at: DOI: 10.1002/14651858.CD006842.pub2 (accessed 12 August 2017)

Spence H, Baker K., et al. (2017). Childhood pneumonia diagnostics: community health workers' and nationalstakeholders' differing perspectives of new and existing aids GLOBAL HEALTH ACTION, VOL. 10, available at: http://www.tandfonline.com/doi/pdf/10.1080/16549 716.2017.1290340 (accessed 10 August 2017)

Contact information

Prof. Nezabravka Gencheva, PhD

Department of Physiotherapy and rehabilitation, National Sports Academy, Sofia

e-mail: nezig@mail.bg

Mobile Tel +359896776604 